\title{
Acceptability and non-compliance in a family-led weight-management programme for obese Pacific children
}

Tasileta Teevale $^{1, *}$, Seini Taufa ${ }^{2}$ and Teuila Percival ${ }^{2}$

${ }^{1}$ Pacific Development Office, Academic Services Division, University of Otago, PO Box 56, Dunedin 9054,

New Zealand: ${ }^{2}$ Pacific Health Section, School of Population Health, Faculty of Medical \& Health Sciences, University of Auckland, Auckland, New Zealand

Submitted 1 February 2014: Final revision received 17 November 2014: Accepted 4 December 2014: First published online 4 February 2015

\begin{abstract}
Objective: To explore factors influencing participation and attrition in a family-led weight-management programme for obese Pacific children.

Design: Qualitative study used bilingual in-depth interviews at exit and end of an 8-week weight-management programme.

Setting: New Zealand.

Subjects: Forty-two parents/primary caregivers of obese children who were randomised in the intervention weight-management programme.

Results: Programmatic factors that enhanced retention included: simultaneous delivery to both children and parents as participants; delivery of the programme in small group settings at local community venues; enabling trustworthy and accountable relationships; providing resources for travel to venues and regular telephone/text messaging follow-up calls reinforcing programme goals; and day and time scheduling. Suggested programme improvements included having ethnic-specific Island-language delivery and practical sessions like cooking classes and shopping expeditions at local food stores. The research found that unpredictable external life crises like extended family deaths, a change in job shift, family illnesses (both acute and those requiring chronic management) and long-term family visitations affected participation and momentum. A loss of momentum through managing life crises was often difficult to overcome for participants, leading them to drop out of the weight-management programme. Most drop-out participants preferred to defer their programme participation with hopes of re-committing to future programmes at another time.

Conclusions: In order for weight-management programmes to be effective, participants must be able to complete them. Identifying factors that predict participation and attrition may serve as a basis for programme improvement.
\end{abstract}

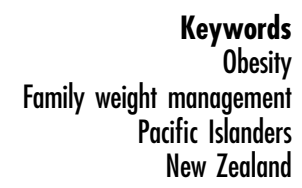

The WHO has declared obesity as a global epidemic with high rates evident in both developed and developing countries $^{(1)}$. The increasing prevalence of the condition in children and adolescents is of particular public health concern as evidence shows a positive association between childhood and adult obesity ${ }^{(2,3)}$. This suggests that the true health impact of obesity may exacerbate in the future, compelling public health ministries to declare obesity reduction as a priority population health objective ${ }^{(4)}$.

New Zealand has the third highest population obesity prevalence among the countries of the Organisation for Economic Co-operation and Development, behind the USA and Mexico $^{(5)}$. Like most developed countries, New Zealand's obesity rates are associated with deprivation, with higher levels observed in low-income groups ${ }^{(6-8)}$. Obesity is a major public health problem for Pacific peoples in New Zealand (comprising a diaspora from the South Pacific islands of Samoa, Cook Islands, Tonga, Niue, Fiji, Tokelau and Tuvalu). The conglomerate Pacific ethnic group occupies the lowest socio-economic strata in New Zealand $^{(9)}$. On average, Pacific peoples have worse economic circumstances than the overall population, with the majority of Pacific peoples living in areas with the fewest economic resources ${ }^{(10)}$. Economically, Pacific New Zealanders are over-represented among the unemployed, lower-skilled workers and the low income-earning group $^{(11)}$. In general, communities with fewer economic resources tend to have poorer health outcomes, as lower incomes mean that many of the conditions or factors that support good health, such as good nutrition and quality housing, are less accessible ${ }^{(12-14)}$. Local evidence has shown how poverty in New Zealand compromises food 
security for these communities and consequently their poorer health status in New Zealand ${ }^{(15-17)}$.

In terms of obesity prevalence, Pacific adults (63.7\%) and children (23.3\%) have an almost threefold higher risk of being obese compared with the general population (26.5\% for adults; $8.3 \%$ for children) ${ }^{(6)}$. There is insufficient evidence about what obesity interventions work for this population group. The purpose of the present research was to investigate the acceptability of a weightmanagement programme for Pacific families with obese children and follow up drop-out participants, to uncover the barriers to programme completion.

Recent reviews on lifestyle interventions for the treatment of obesity in children have concluded that moderateto high-intensity behavioural lifestyle programmes can reduce the level of paediatric obesity ${ }^{(18,19)}$. However, despite sustained efforts in the development of weightmanagement programmes to address childhood obesity, threats to efficacy include: low adherence to treatment cycles; behavioural relapse leading to weight regain; and high levels of attrition in interventions ${ }^{(20)}$. Evidence suggests that in order for weight-management programmes to be effective, participants need to complete the full duration of the programme ${ }^{(19,21-23)}$. Inversely, premature termination from a weight-management programme results in incomplete health care for patients that can lead to failure experiences for both patients and health-care providers $^{(24)}$.

Non-compliance in weight-management programmes for children is a major concern for intervention studies. Within the current literature, many intervention studies do not report on factors that lead to participant drop-out in weightmanagement programmes ${ }^{(22)}$. The 2009 Cochrane review found for those studies that reported drop-out rates in childhood obesity interventions, the non-completion rate was as high as $42 \%$ (range $0-42 \%$ ). The drop-out rate at 6, 9 and 12 months post-intervention follow-up stages was in the range of $1-42 \%, 8-34 \%$ and $7-43 \%$, respectively ${ }^{(19)}$. More recently, studies have delved into identifying participant- or patient-level predictors of attrition. Clinic-based weightmanagement programmes, namely from North America, that reported on patient experiences informed that common factors for non-completion, including medical insurance status, African-American ethnicity, older age, depression, elevated parental BMI, overall health status, location and timing of programme delivery, unfulfilled parental and child expectations of weight loss and multiple previous weightloss attempts in women, also predicted attrition ${ }^{(25-30)}$. Fewer community-based weight-management interventions report on participant experiences leading to non-completion. Other possible non-completion factors in community-based lifestyle modification programmes include fear of weight stigmatisation, cultural incongruence between participants and providers, and imprecise programme intensity and duration $^{(24,31,32)}$. The present study aimed to uncover the factors influencing both participant retention and conversely non-completion in a family-led weight-management programme for obese Pacific children in New Zealand. Improving participant retention and minimising attrition are crucial for individual participant success and critical for demonstrating programme efficacy, as well as quality improvement.

\section{Methods}

\section{Study design}

A qualitative research approach was favoured as it allowed the topic to be explored in depth. Semi-structured faceto-face interviews were completed with parents of obese children who were randomised into the intervention arm of the FANAU FAB weight-management programme. The title of the programme used the Samoan word fanau which translates to the word 'children' and the acronym FAB for Food, Activity and Behaviour. FANAU FAB was a parallel randomised controlled trial for obese Pacific children aged 5-12 years and their parent/primary caregiver. The community-based lifestyle behavioural modification programme involved eight weekly group therapy sessions of 90 min duration, delivered in local community venues (schools and churches) in South Auckland, New Zealand. South Auckland was chosen as the region for programme delivery as almost $70 \%$ of Pacific New Zealanders live in Auckland city (177 936) with over one in four living in the South Auckland region. South Auckland is classed as a high deprivation socio-economic area ${ }^{(10)}$. The FANAU FAB programme was guided by the theories of cognitive behavioural modification education used in similar familybased weight-management programmes ${ }^{(33-35)}$. At each session, both parents/primary caregivers and children would engage in a family activity in the first half-hour of each session. For the rest of the programme time, children were engaged separately in games and informational activities while their parents/primary caregivers were supported with information, goal-setting tasks and group processes of sharing their lived experiences around FAB (Food, Activity and Behaviour). Upon completion of the 8-week programme, families received maintenance support for 26 weeks, which involved one home visit per family and one follow-up telephone call and/or text message per week. Participant drop-outs were defined as families that completed $\leq 4$ weeks out of the 8-week programme.

Forty-two parents completed post-intervention faceto-face semi-structured interviews. The average age range of participants was 36-45 years. Sampling continued until few new insights were achieved from subsequent interviews. Indigenous Pacific research principles, cultural processes and strategies were followed for interviews ${ }^{(36)}$. Three bilingual researchers in Samoan and Tongan language conducted the interviews. Interviewers familiarised themselves with the participants during their first 
and last session of the programme to explain the qualitative follow-up study. Interviewers then contacted each parent interviewee by telephone, email or faceto-face via door knocking, to schedule interviews to be held at a location of the participant's choosing. Most interviews took place at the participants' home and a few were held at their local church. Each interview lasted approximately $60 \mathrm{~min}$ and was recorded with consent, transcribed verbatim and then translated into English language. Participants were offered a \$NZ 20 supermarket voucher as a token of appreciation.

The study was conducted according to the guidelines laid down in the Declaration of Helsinki and all procedures involving human subjects/patients were approved by the University of Auckland Human Subject Ethics Committee. Written informed consent was obtained from all participants and identities are protected through the use of pseudonyms in this manuscript and any other published material.

Participants completed a demographic form that captured household size, number of dependant children, birthplace, parental status, household employment status, household income, age range, ethnicity and languages spoken at home. Table 1 summarises the participants' demographic profile.

\section{Materials}

Two interview schedules were prepared, one for those participants who completed the 8-week programme and one for those who had dropped out of the programme. For completers, the scope of the interview included questions on their child's overall health, physical, emotional and social well-being, the child's weightmanagement history and the child's overall progress in the weight-management programme. Questions on the programme included programme awareness (recruitment into the programme) and aspects of the weightmanagement programme including materials provided, information content, organisation, personnel and delivery. Participants were asked to identify what aspects of the programme were acceptable and why; and in concert, what aspects were deemed ineffective for changing food and physical activity behaviours in the home environment. Participants were asked questions about the effect of the programme on their child's and their own weight management and aspects of the programme they found difficult. The interviews ended with questions on suggested future improvements of the programme.

The scope of questions posed to drop-out participants included questions on their child's health status, programme awareness and recruitment, length of time on the programme and initial programme expectations. Participants then assessed each programme feature listed (materials provided, organisation, information content, personnel and delivery) depending on the length of their participation. For example, those participants who attended only one or two out of the eight weekly sessions would have experienced very minimal contact time at the weekly session(s), and this influenced their commentary. Reasons for non-completion were elicited, as well as future intent and suggestions on programme improvements.

\section{Analysis}

Thomas $^{\text {(37) }}$ general inductive approach for analysis of qualitative evaluation data was used as the analysis framework. The general inductive approach provides a simple, straightforward approach for deriving findings in the context of focused evaluation questions. Two researchers reviewed each transcript and condensed the raw textual data using focused evaluation questions to guide the analysis. The purpose of the analysis was to categorise, summarise and present key themes in order of importance to participants. All available data were analysed to fit within evaluation research questions' objective headings. The computer software program NVivo7 was used to analyse, sort and code the interview data.

\section{Results}

Table 1 shows the demographic details of study participants. The majority of participants were women who had not been born in New Zealand (85\%), and included mothers, aunts and grandmothers. Participants of Tongan ethnicity were most numerous, although $30 \%$ of the participants were from multi-ethnic households. The average household size was $6 \cdot 3$ (range 1-11); the average number of dependant children per household was $3 \cdot 1$ (range 1-7). Eighty-five per cent of the participants were from two-parent households and $85 \%$

Table 1 Demographic details of Pacific parents/primary caregivers ( $n$ 42), participants in the family-led FANAU FAB weightmanagement programme for obese Pacific children, New Zealand

\begin{tabular}{lrr}
\hline Demographic variable & $n$ & $\%$ \\
\hline Gender & 36 & \\
$\quad$ Female & 6 & $85 \cdot 0$ \\
Male & 14 & $15 \cdot 0$ \\
Age range (years) & 15 & $33 \cdot 3$ \\
18-35 & 7 & $35 \cdot 7$ \\
$36-45$ & 6 & $16 \cdot 6$ \\
$46-55$ & & $14 \cdot 4$ \\
$56-65$ & 6 & \\
Birthplace & 36 & $85 \cdot 0$ \\
New Zealand & & \\
Outside New Zealand & 19 & $45 \cdot 4$ \\
Ethnicity* & 15 & $7 \cdot 0$ \\
Tongan & 3 & $7 \cdot 1$ \\
Samoan & 3 & $2 \cdot 3$ \\
Cook Island & 1 & $7 \cdot 1$ \\
Niuean & 3 & \\
Fijian & & \\
New Zealand Maori & & \\
\end{tabular}

${ }^{\star}$ Ethnicity-all-count, so percentages do not add to $100 \%$. 
were employed households. The average estimated household income, not equivalised to household size, was $\$ \mathrm{NZ}$ 50000-60000. Ninety per cent of the sample spoke an Island language at home; $60 \%$ spoke at least two languages in the home.

\section{Programme awareness and initial programme expectations}

Participants identified the following ways they were recruited into the FANAU FAB weight-management research programme: through referral from their local school nurse; receiving a school newsletter home; hearing a church notice or announcement made after Sunday church service; through a doctor referral from a Pacific health provider; reading an advertisement in the local newspaper; receiving word-of-mouth information from a family member; and through interaction with a research project recruiter at a local shopping mall.

Parents were attracted to enlist in the weightmanagement programme because it was 'family-based' and therefore parents and children could actively participate together and provide support to each other. As one mother said: 'I thought that it was good, 'cause he and I were doing it together, and he wasn't doing it on his own' (Tani, Cook-Island mother). Parents' reasons for joining the programme included: addressing their child's obesity for health reasons; to prevent a family history of diabetes; for children to be more active and gain energy; and to mitigate teasing and bullying for their overweight child. Some participants had expectations of a culturally delivered programme and were attracted to the programme because of its Pacific name.

\section{Acceptable programme features}

We identified four key themes from the data that participants identified as satisfactory programme features that had impacted their retention: (i) the simultaneous delivery of the programme to both children and parents; (ii) having trustworthy and accountable relationships among programme personnel and between participants; (iii) location of venues and receiving financial support to travel to programme venues; and (iv) receiving regular reminder telephone calls/text messages and supportive personal home visits. Table 2 outlines these four themes with representative quotes from participants illustrating each theme.

\section{Reasons for dropping out}

The primary influencer on non-completion was an unpredictable lifestyle event that impacted participants' time commitment to complete the programme. Changes in work schedules and work shifts at short notice severely impacted parents' retention in the programme. Transport issues and having to rely on other working family members as drivers to attend the programme caused missed sessions. Cultural obligations like meeting extended family needs also had an impact on programme participation as illustrated by the following collection of quotes:

'We missed the last few weeks, 'cause actually we had a funeral and we weren't able to attend.' (Ani, Tongan mother)

'It became difficult when my husband's work shift changed, he couldn't be home to look after the family [members], so I had to stay home and we couldn't do the programme.' (Lana, Cook-Island mother)

'Because my baby was sick, in the hospital, so we missed the last four sessions.' (Mata, Samoan mother)

'The only reason why I pull out from the programme was because my [elderly] mum came from the islands to stay with us ... and there's no one to look after her here at home.' (Rosa, Samoan mother)

\section{Suggested future programme improvements}

Several participants talked about increasing the programme duration from 8 weeks to 12 weeks most commonly. This was related mainly to group members feeling like they needed more support for behavioural change, both for the child and for adults. As one mother stated, this was 'so that the children can get more involved as a group with other children of the same age. If there was just maybe an extension group for the kids, bring in another activity or group thing to do, to keep them more together' (Tala, Tongan mother).

'I wish it could have been like 12 weeks, longer. Because like, just being in the programme, keeps you motivated, 'cause when you do it by yourself, just doing it yourself at home, it's kind of hard. But when you have a group and you're always there, it motivates you 'cause you're hearing other people share their stories.' (Loseta, Cook-Island mother)

'I still think that the 8 weeks was enough, but 'cause some of us were worried we weren't going to do it [on our own] because we're so used to doing it every week.' (Pania, Fijian mother)

Additionally, most participant suggestions for future programme improvements were related to more practical hands-on sessions like cooking demonstrations and healthy food shopping expeditions:

'I would have loved it if there was a session on cooking, like, get in a chef or someone, a dietitian, to come, because its different, saying "take the fat from like the corn beef", with actually showing it to the people. Those kind of things, like the portion sizes, come and show us the portion size, instead of maybe if the plate is this big, but actually show portion sizes to the parents so they can see it for themselves, see it being done.' (Sana, Tongan mother) 
Table 2 Acceptable weight-management programme features and their representative quotes extracted from qualitative interviews with Pacific parents/primary caregivers ( $n$ 42), participants in the family-led FANAU FAB weight-management programme for obese Pacific children, New Zealand

Theme Representative quotes

(i) Simultaneous delivery of the programme to both children and parents

(ii) Having trustworthy and accountable relationships among programme personnel and between participants

(iii) Location of programme venues and receiving financial support to travel to programme venues

(iv) Receiving regular reminder telephone calls/text messaging and supportive personal home visits
"Being there and doing it together with my son, he would ask me after a session "What did you guys do?" and l'd say, "We learnt this, we learnt that". So sharing what we did in the programme really grabbed his attention and he wanted to do it. If I tried to say or do the programme all by myself without him, it would be hard.' (Liana, Niuean mother)

'When the information we both got was the same, it made us work together [child and parent] to help each other.' (Sue, Tongan mother)

'There was a time when my daughter would say, "I don't want to go, 'cause they're telling me I can't eat this and can't eat that". And I go, "No we'll go, 'cause they're telling me the same thing". When she saw it was difficult for me too and we started getting into a routine, she started wanting to go.' (Pania, Fijian mother)

'Sometimes, l'd be like "Aww, I don't want to [go]", and some weeks he [son] wouldn't want to go, but we stuck it out and eventually got through it. One of us would want takeaways at a busy moment, and the other would say "No, let's get Subway, choose the healthy option", it was good support.' (Losa, Samoan mother)

'The truth is I wanted to join the programme for my son, but when the programme started, during the first week, I realised that it wasn't just my son that needed to change, I needed to change too. Because if I, as the mother, learnt how to prepare food, because l'm the one that does the shopping, and so my family will become healthier. And if I don't understand how to look after my family's health, then Isa [son] won't learn from it.' (Telusila, Tongan mother)

'I really liked the group atmosphere. How it was like run, and everybody went around the circle, and we all shared our stories of the week, and we all came together each week and shared with each other our struggles and triumphs of the weeks. And after the 8 weeks we all knew each other and we became very fond of each other, because we'd gone through the same, we were all there for a similar purpose. So I really liked the group part.' (Yolanda, Niuean mother)

'And us making each other accountable, catching up with each other with the buddy system. The buddy system is good because sometimes my buddy would tell me her ideas and you go "ok then", and you try it and it helps, which is really good. Sometimes my buddy is good, when they text "'m up the mountain walking" and you thinking "oh I got to go too", it's like encouraging each other.' (Salu, Samoan aunt)

"Cause sometimes you struggle by yourself and you think that you're the only one - does anyone else struggle like me, but when we discuss it in groups then you hear, its normal. I think I really liked the group discussion because you know where you are with other people.' (Luana, Tongan mother)

'And having the group there saying, "yeah you can do it!", then l'll do this and try that, so it really helped, I felt the support.' (Carol, Cook-Island aunt)

Yes, I like that it's here [delivered at local church]. If it's here, everyone would come, I don't think it would work if it were somewhere else, and if it was with a different group of people maybe, but because we're all part of the church its better here. (Helu, Tongan grandfather)

'When you're familiar with that place, like at our own church, we feel more comfortable staying here because we always feel at home in our own place.' (Susi, Tongan mother)

'The venue being at school makes it easier to attend, especially because my kids are from that school.' (Julie, Cook-Island mother)

'The programme was good and very enjoyable, like with the little bit of help that they gave us to get to the programme. Like the things they gave us for petrol [vouchers]. Maybe that's why some people came, maybe if there weren't any help for transport, they wouldn't come.' (Ane, Tongan mother)

'Yes, during the weekends, the study people would ring and remind us of Monday, remind us weekly about our next session.' (Loto, Tongan mother)

Yeah, we got phone calls and yeah, 'cause they checked why we didn't show up, so they'd call and ask us if we were alright and stuff and if we were still exercising.' (Tala, Tongan mother)

'We had partners, we'd text our partners about what they were doing, how many steps they did in a day, what they were eating. It was in pairs and even it was helpful when my daughter goes to that kid, the kid tells her how much they've lost. It's like she wants to lose weight because her friend loses weight.' (Lole, Tongan mother) 
'If they had planned it where we were actually active, you know [say to us] "okay parents this is the scenario, there's your [local] shopping centre over there and this is how much you're going to spend". And actually get us up and moving, going in with say 20 dollars to spend, and learning to create a family meal for what I can buy. That would have been good.' (Varia, Cook-Island mother)

Much feedback was received on better culturally specific delivery of the programme. There was a clear language and therefore cultural barrier, especially for the programme delivered to one specific Island ethnic group:

'For me if it were delivered in Tongan it would have been clearer, because the majority of us may not understand English. Remember, when it comes to the discussions, there are some that can speak English and others who can't. There were times when we asked if it could be translated, and I think that time was wasted on translations. I remember they asked us questions and I hardly said anything ... we're shy people.' (Eli, Tongan grandfather)

Aspects of a culturally appropriate Pacific programme were further suggested. A Pacific tailored approach was explained by one participant to be practical and grounded in real-life experiences. Many participants indicated a preference for 'Pacific families that had gone through what you're going through, come in and kind of tell you what they'd gone through, and what they'd learnt and what helped them. This would have helped me. ...We're more the "do" than the sit down [approach]. ... Like we're all brown faces, but it was evident that it was coming from a Palagi model. The types of questions that we were being asked, was like we were kind of ticking boxes, and that's what it felt like sometimes. 'Cause they were looking at their papers, and just going through theory. And you don't want to hear theory when you're a mum. You want to hear real-life experience and what's practical for us as Pacific people' (Ata, Samoan mother).

There was a gender trend with the men participants indicating a preference for more physical activity/exercise inclusion as part of the programme, while the women were satisfied with the original predominantly discussions format.

One of the suggestions for future change was to include many more family members as part of the programme. This was to alleviate what most in the programme identified as the most difficult aspect of making household family-based food and activity changes: familial sabotage. As represented by the quote below, when other parents and children in the same household were not exposed to the programme, it proved difficult for participants to effect change in the home environment:

'The thing I found most difficult was facing my family. During the first week, my kids weren't use to the proportions I gave them on their plate. The biggest problem was my husband, because I'd try to cut back on the fizzy drinks but he goes and brings fizzy drinks ... It was a lot more helpful, and easier when we were both part of it [weight-management programme] because we came to have a mutual understanding and about the importance of being healthy.' (Telusila, Tongan mother)

Most participants confirmed that a programme scheduling of once weekly was sufficient and timemanageable. Programme delivery over both school term and school holidays was not problematic and timing for after-school or after-work hours was also preferred. Having the programme delivered on a weekday was favoured because families had obligations to meet on weekend days, like church and sporting activities.

\section{Unintended benefits of the programme}

Most participants explained that their initial expectations were only for their child to receive benefits from attending the programme. That is, that the weight loss and physical health benefits would accrue to their child only. Most participants were therefore pleasantly surprised at their own weight-loss achievements from the programme, as illustrated below:

'When I started this programme, I was $89 \mathrm{~kg}$ but now it's going down to $84 \mathrm{~kg}$ at the moment, which I thought "wow". ... Yeah, which I think it's more from the activity and like portioning our food.' (Faafetai, Samoan mother)

These unintended weight-loss experiences for parents spurred them on for more household health changes, applying changes in the home that affected other family members, who were then encouraged by their physical health changes and their role modelling within the home:

'Eventually all our kids came and joined in; so we've got a 12 -year-old and a 7-year-old and a 5-year-old; so they all came and do the exercise and that. So even the older one, she's also watching what she's eating now since we've done this, a lot more than before.' (Carol, Cook-Island mother)

Being part of the programme gave some participants greater social engagement and they made new friends. Some participants with other children identified that the service provided by the programme for child care during the session enabled them to attend.

\section{Discussion}

The factors that influenced participant retention in a family-led weight-management programme for obese Pacific children included the strong emphasis on family and group participation and sharing learning experiences in tandem between children and parents. The shared experience and the adult role modelling seemed effective 
for children's motivation to participate. In addition, the way in which children were able to encourage parents to attend or to hold firm in behavioural change was an unfamiliar finding. Parental modelling has been found in the literature to be effective in controlling children's nutrition and weight control ${ }^{(23,33,38,39)}$, while the way in which reciprocal social support was enacted from child to parent was interesting to find in the present project.

Participants alluded to being attracted to the weightmanagement programme through its emphasis on delivering a model suitable for a cultural group. As suggested programme improvements, having ethnic-specific Islandlanguage delivery, having successful Pacific weight-loss role-model families and having more practical sessions (e.g. cooking classes and shopping expeditions at local food stores using a budget) were the particular features identified by participants in the trial. The study participants alluded to being attracted to joining the programme because it was targeting their particular ethnic grouping: Pacific. In this sense, they had expectations that its delivery would include some specific differences compared with, in their own words, 'Palagi' or non-Pacific mainstream Western models of delivery. Having information content delivered in a Pacific-Island language and having successful Pacific weight-loss role models were their particular recommendations for future programme delivery. In addition, having a programme with more practical application of theory or informational content (like food cooking demonstrations or food shopping expeditions) was also deemed more specifically 'cultural' than mainstream or typical models of programme delivery. Interestingly, the ideas for practical elements to be included in future programmes have been tested in other health interventions with promising results ${ }^{(40,41)}$. Hands-on cooking experiences were found to be more effective in retention of nutritional knowledge and consequential application in home cooking ${ }^{(42)}$. In addition, supermarket or food shopping tours have been used by other low-income population groups, showing positive effects in making healthy food choices ${ }^{(43-45)}$. Previous trials have identified that cultural dissonance in programme delivery predicted attrition ${ }^{(28,46,47)}$. The present study makes a contribution in identifying programmatic elements that could be modified to enhance retention for this at-risk group.

Additionally, the focus of the study was also to uncover the factors that predicted attrition in a family-led weightmanagement programme for obese Pacific children in New Zealand. The literature on community-based programme attrition can be described as currently being undersized. The present research found that unpredictable external life crises like extended family deaths, a change in job shifts, family illnesses (both acute and those requiring chronic management) and long-term family visitations affected participation and momentum. A loss of momentum through managing life crises was often difficult to overcome for participants, leading them to drop out of the weight-management programme. Uncovering previously unknown factors that predict non-completion is a necessary step to programme improvement. Interventionists can assess how these factors can be addressed for future programmes. The present study found that most drop-out participants preferred to defer their programme participation with hopes of re-committing to future programmes at another time. This recommendation from participants highlights the discordance between interventional weight-management programmes implemented for research purposes $v$. real-life scenarios which can often be successfully addressed in clinical settings. Our research study had to limit its definition of 'participant' and 'drop-out' because it was interested in capturing dose-and-effect outcomes in a limited-time intervention programme. In real-world settings, it is recommended for weight-management programmes to have rolling retention policies and procedures, to enable participants to be captured in the programme and to allow flexibility in their entry and exit. Like other behavioural change programmes in the health arena, for example in smoking ${ }^{(48)}$ or alcohol management ${ }^{(49)}$, weight management also involves periods of relapse and re-commitment ${ }^{(50-52)}$ that can be difficult to capture in limited-time research interventions. Our study enabled us to explore, with the participants, how they felt they could manage their programme participation in the face of trying to manage life crises and changes. Keeping in contact with drop-out participants over time and inviting them to re-enter future programmes is recommended.

\section{Conclusions}

Given the elevated and inequitable obesity risk for both child and adult Pacific New Zealanders, the results of the present research project will be of value in informing public health responses to addressing obesity risk in this population group. To the authors' knowledge, no other evidence has been presented on the factors that predict attendance and attrition in weight-management programmes for this at-risk group. Identifying elements critical to producing efficacious weight-management programmes within the community has the potential to produce better and equitable health outcomes.

\section{Acknowledgements}

Acknowledgements: The authors thank the community interviewers, Ingrid Tanoa and Helen Tagaloa, for their research assistance. They also thank the FANAU FAB research team, Dr Ofa Dewes, Dr John Sluyter and Mr Gavin Faeamani, of the Pacific Health Department, University of Auckland, New Zealand. Financial support: HRC Post-doctoral Career Development Award, Pacific Health Department, University of Auckland for T.T. This work was supported by a grant from the Health Research Council of New Zealand. The Health Research Council of New Zealand 
had no role in the design, analysis or writing of this article. Conflict of interest: None. Authorship: T.T. designed the study, conducted interviews, analysed the transcripts and wrote the manuscript, S.T. conducted interviews, analysed the transcripts and contributed to the final manuscript, T.P. had overview of the project and contributed to the final manuscript. Ethics of human subject participation: The University of Auckland Human Subject Ethics Committee granted ethical approval for the study.

\section{References}

1. World Health Organization (2000) Obesity: Preventing and Managing the Global Epidemic. Report of a WHO Consultation. WHO Technical Report Series no. 894. Geneva: WHO.

2. Freedman DS, Khan LK, Serdula MK et al. (2005) The relation of childhood BMI to adult adiposity: the Bogalusa Heart Study. Pediatrics 115, 22-27.

3. Serdula MK, Ivery D, Coates RJ et al. (1993) Do obese children become obese adults? A review of the literature. Prev Med 22, 167-177.

4. Ministry of Health (2000) The New Zealand Health Strategy. Wellington: Ministry of Health; available at http://www. health.govt.nz/system/files/documents/publications/new zealandhealthstrategy.pdf

5. Organisation for Economic Co-operation and Development (2013) Health at a Glance 2013: OECD Indicators. http:// www.oecd.org/els/health-systems/Health-at-a-Glance-2013. pdf (accessed January 2015).

6. Ministry of Health (2008) A Portrait of Health: Key Results of the 2006/07 New Zealand Health Survey. Wellington: Ministry of Health.

7. World Health Organization (2003) Diet, Nutrition and the Prevention of Chronic Diseases. Report of a Joint WHO/FAO Expert Consultation. WHO Technical Report Series no. 916. Geneva: WHO.

8. Organisation for Economic Co-operation and Development (2012) Obesity update 2012. http://www.oecd.org/health/ 49716427.pdf (accessed January 2014)

9. Statistics New Zealand (2006) Quick Stats About Pacific Peoples Census 2006. http://www.stats.govt.nz/Census/ 2006CensusHomePage/QuickStats/quickstats-about-a-subject/ pacific-peoples.aspx (accessed January 2015).

10. Crampton P, Salmond C, Kirkpatrick R et al. (2000) Degrees of Deprivation in New Zealand. An Atlas of Socioeconomic Difference. Auckland: David Bateman.

11. Ministry of Pacific Island Affairs (2002) Current Trends \& Economic Status of Pacific Peoples. Wellington: Ministry of Pacific Island Affairs.

12. Ministry of Social Development (2010) The Social Report 2010. Te pürongo oranga tangata 2010: Indicators of Social Wellbeing in New Zealand. Wellington: Ministry of Social Development.

13. Statistics New Zealand \& Ministry of Pacific Island Affairs (2011) Health and Pacific Peoples in New Zealand. Wellington: Statistics New Zealand and Ministry of Pacific Island Affairs.

14. Casey PH, Simpson PM, Gossett JM et al. (2006) The association of child and household food insecurity with childhood overweight status. Pediatrics 118, e1406-e1413.

15. Rush E, Puniani N, Snowling N et al. (2007) Food security, selection, and healthy eating in a Pacific community in Auckland New Zealand. Asia Pac J Clin Nutr 16, 448-454.

16. Lanumata T, Heta C, Signal L et al. (2008) Enhancing Food Security and Physical Activity: The Views of Maori, Pacific and Low-Income Peoples. Wellington: Health Promotion and Policy Research Unit, University of Otago.
17. Teevale T, Thomas DR, Scragg R et al. (2010) The role of sociocultural factors in obesity etiology in Pacific adolescents and their parents: a mixed-methods study in Auckland, New Zealand. $N Z$ Med J 123, 26-36.

18. Whitlock EP, O'Connor EA, Williams SB et al. (2010) Effectiveness of weight management interventions in children: a targeted systematic review for the USPSTF. Pediatrics 125, e396-e418.

19. Oude Luttikhuis H, Baur L, Jansen H et al. (2009) Interventions for treating obesity in children. Cochrane Database Syst Rev issue 1, CD001872.

20. Theim KR, Sinton MM, Goldschmidt AB et al. (2013) Adherence to behavioral targets and treatment attendance during a pediatric weight control trial. Obesity (Silver Spring) 21, 394-397.

21. Hampl S, Paves H, Laubscher K et al. (2011) Patient engagement and attrition in pediatric obesity clinics and programs: results and recommendations. Pediatrics 128, Suppl. 2, S59-S64.

22. Skelton JA \& Beech BM (2011) Attrition in paediatric weight management: a review of the literature and new directions. Obes Rev 12, e273-e281.

23. Wrotniak BH, Epstein LH, Paluch RA et al. (2005) The relationship between parent and child self-reported adherence and weight loss. Obes Res 13, 1089-1096.

24. Grimes-Robison C \& Evans RR (2008) Benefits and barriers to medically supervised pediatric weight-management programs. J Child Health Care 12, 329-343.

25. Barlow SE \& Ohlemeyer CL (2006) Parent reasons for nonreturn to a pediatric weight management program. Clin Pediatr 45, 355-360.

26. Kitscha CE, Brunet K, Farmer A et al. (2009) Reasons for non-return to a pediatric weight management program. Can $J$ Diet Pract Res 70, 89-94.

27. Skelton JA, Goff DC Jr, Ip E et al. (2011) Attrition in a multidisciplinary pediatric weight management clinic. Child Obes 7, 185-193.

28. Tershakovec AM \& Kuppler K (2003) Ethnicity, insurance type, and follow-up in a pediatric weight management program. Obes Res 11, 17-20.

29. Walker SE, Smolkin ME, O'Leary ML et al. (2012) Predictors of retention and BMI loss or stabilization in obese youth enrolled in a weight loss intervention. Obes Res Clin Pract $\mathbf{6}$, e330-e339.

30. Cote MP, Byczkowski T, Kotagal U et al. (2004) Service quality and attrition: an examination of a pediatric obesity program. Int J Qual Health Care 16, 165-173.

31. Jelalian E, Hart CN, Mehlenbeck RS et al. (2008) Predictors of attrition and weight loss in an adolescent weight control program. Obesity (Silver Spring) 16, 1318-1323.

32. Williams NA, Coday M, Somes G et al. (2010) Risk factors for poor attendance in a family-based pediatric obesity intervention program for young children. J Dev Behav Pediatr 31, 705-712.

33. Golan M (2006) Parents as agents of change in childhood obesity - from research to practice. Int J Pediatr Obes $\mathbf{1}$, 66-76.

34. Patrick H \& Nicklas TA (2005) A review of family and social determinants of children's eating patterns and diet quality. J Am Coll Nutr 24, 83-92.

35. Heinberg LJ, Kutchman EM, Berger NA et al. (2010) Parent involvement is associated with early success in obesity treatment. Clin Pediatr 49, 457-465.

36. Health Research Council of New Zealand (2005) Guidelines on Pacific Health Research. Auckland: Health Research Council of New Zealand.

37. Thomas DR (2006) A general inductive approach for analyzing qualitative evaluation data. Am J Eval 27, 237-246.

38. Campbell KJ, Crawford DA, Salmon J et al. (2007) Associations between the home food environment and 
obesity-promoting eating behaviors in adolescence. Obesity (Silver Spring) 15, 719-730.

39. Brown R \& Ogden J (2004) Children's eating attitudes and behaviour: a study of the modelling and control theories of parental influence. Health Educ Res 19, 261-271.

40. Kahn RF, O'Sullivan P \& Vannatta PM (2003) Supermarket tour: the effect of presentation mode on nutrition knowledge and attitudes. Fam Med 35, 721-725.

41. Baic S \& Thompson JL (2007) Prevent It: using grocery store tours as an educational tool to promote heart health. ACSM Health Fit J 11, 15-20.

42. Levy J \& Auld G (2004) Cooking classes outperform cooking demonstrations for college sophomores. J Nutr Educ Behav 36, 197-203.

43. Carson JAS \& Hedl JJ (1998) Smart shoppers tours: outcome evaluation. J Nutr Educ 30, 323-331.

44. Rosal MC, White MJ, Restrepo A et al. (2009) Design and methods for a randomized clinical trial of a diabetes selfmanagement intervention for low-income Latinos. BMC Med Res Methodol 9, 81.

45. Liebman J, Heffernan D \& Sarvela P (2007) Establishing diabetes self-management in a community health center serving low-income Latinos. Diabetes Educ 33, Suppl. 6, 132S-138S.
46. Carroll JK, Yancey AK, Spring B et al. (2011) What are successful recruitment and retention strategies for underserved populations? Examining physical activity interventions in primary care and community settings. Transl Behav Med 1, 234-251.

47. Yancey AK, Ortega AN \& Kumanyika SK (2006) Effective recruitment and retention of minority research participants. Annu Rev Public Health 27, 1-28.

48. Garvey AJ, Bliss RE, Hitchcock JL et al. (1992) Predictors of smoking relapse among self-quitters: a report from the normative aging study. Addict Behav 17, 367-377.

49. Brown SA, Vik PW, Patterson TL et al. (1995) Stress, vulnerability and adult alcohol relapse. J Stud Alcohol 56, 538-545.

50. Kaholokula JK, Mau MK, Efird JT et al. (2012) A family and community focused lifestyle program prevents weight regain in Pacific Islanders: a pilot randomized controlled trial. Health Educ Behav 39, 386-395.

51. Jeffery RW, Drewnowski A, Epstein LH et al. (2000) Longterm maintenance of weight loss: current status. Health Psychol 19, 1 Suppl., 5-16.

52. Wing RR \& Phelan S (2005) Long-term weight loss maintenance. Am J Clin Nutr 82, 1 Suppl., 222S-225S. 